\title{
Is a Divergent Central Serotonergic Activity Responsible for Either Despair or Learning Behavior in Intact Wistar or Sprague-Dawley CD Rats, Respectively? A Concomitant Behavioral and Electrochemical Analysis
}

\section{Francesco Crespi}

Biology Deparment, Neurosciences CEDD GlaxoSmithKline, Medicines Research Centre, Verona, Italy. Email: francesco.m.crespi@gsk.com

Received May 11 ${ }^{\text {th }}, 2010$; revised June 28 ${ }^{\text {th }}, 2010$; accepted June $30^{\text {th }}, 2010$.

\begin{abstract}
Behavioral observations combined with electrochemical analysis have been performed in Wistar or Sprague-Dawley $C D$ rats in the attempt to clarify earlier controversial behavioral reports. In particular, these rats were submitted to FST and to repeated Forced Swimming ( $r F S$, during 4 days). In parallel, voltammetric in vivo analysis of serotonin (5-HT) levels in platelet-rich plasma (PRP) collected daily from these animals was also performed as it is known that peripheral 5-HT levels monitored in rat PRP mirror cerebral 5-HT contents. Thus, combined behavioral-voltammetric studies allow deducing changes of central 5-HT levels that could be correlated to FST or rFS, with the advantage of non invasive analysis of central neurotransmitter activities in intact behaving animals. In particular, combined behavioral-voltammetric results suggest that "behavioral despair" is the process interesting Wistar rats when submitted to FST or rFS while "learning to be immobile" is the process involving Sprague-Dawley CD rats.
\end{abstract}

Keywords: Rat Strains, Behavior, Electrochemistry, Fluoxetine, Serotonin, Platelets

\section{Introduction}

Many studies employing the forced swimming test (FST) which is a behavioral test that predicts the clinical efficacy of many types of antidepressant drugs [1] have been done using Sprague-Dawley CD rats. A minor number of such experiments have been done in Wistar rats. In the Sprague-Dawley CD strain of rodents submitted to FST in $15 \mathrm{~cm}$ water depth [2-5] or $30 \mathrm{~cm}$ water depth [6-10] an antidepressant drug such as the selective serotonin reuptake inhibitor (SSRI) fluoxetine produced dose-dependent reduction of immobility at doses ranged between 5 or $80 \mathrm{mg} / \mathrm{kg}$.

An antidepressant drug such as the selective serotonin reuptake inhibitor (SSRI) fluoxetine at doses ranged between 5 or $80 \mathrm{mg} / \mathrm{kg}$ produced dose-dependent reduction of immobility in Sprague-Dawley CD rats submitted to FST performed in $15 \mathrm{~cm}$ water depth [2-5] or in $30 \mathrm{~cm}$ water depth [6-10]. In contrast, treatment with fluoxetine increased immobility in Wistar rats tested in deep water
$(30 \mathrm{~cm})[11,12]$ while a decrease or no modification of immobility was monitored when FST was performed in $15 \mathrm{~cm}$ water depth $[13,14]$. Thus, following treatment with fluoxetine, differences in immobility behavior between these two strains of rodents appear when tested in lower water $(15 \mathrm{~cm})$ and become evident when tested in deeper water $(30 \mathrm{~cm})$. Again, in Sprague-Dawley CD rats peripheral fluoxetine (from 5 to $20 \mathrm{mg} / \mathrm{kg}$ ) significantly and dose-dependently increased swimming behavior $[6,7$, 11] while in Wistar rats only the highest dose of fluoxetine did so [11]. Conversely, fluoxetine did not alter climbing at any dose tested $(5-80 \mathrm{mg} / \mathrm{kg})$ in any of the two rat species [4,6,8-11].

It is known that the swimming behavior is closely related to the activity of cerebral 5-HT [4,6]. Thus, one can propose that the different sensitivity to fluoxetine behaviorally displayed by the two strains may be related to dissimilarity within their serotonergic system.

The current study has been undertaken to analyse this hypothesis. Sprague-Dawley and Wistar rats have been 
submitted to FST in deep water $(30 \mathrm{~cm})$ after intraperitoneal treatment with saline (vehicle) or with fluoxetine $20 \mathrm{mg} / \mathrm{kg}$ as this appears to be the dose significantly affecting the swimming behavior within both types of rodents [11]. Deep water has been selected as in such conditions rats cannot support themselves by touching the ground and they are obliged to swim and/or climb more actively $[4,6]$. Furthermore, the duration of the swimming test was prolonged up to a total of 4 days [15]. This has been done since previous reports have observed development of habituation in Wistar rats submitted to repeated FST [16-18] and that pharmacological blockade of serotonergic activity enhances learning and memory skills $[19,20]$. Those reports were followed by other studies with the subsequent suggestion that the process involved in FST could be "learning to be immobile" $[21,22]$ more than "behavioral despair" $[1,3,4]$. In the present work, application of rFS to Sprague-Dawley and Wistar rats together with electrochemical analysis of in vivo serotonergic activities would investigate this hypothesis. In particular, voltammetric measurements of 5-HT have been performed in PRP obtained from blood collected from the tail vein of naive or "treated" conscious Sprague-Dawley or Wistar rats, daily.

Many clues in the literature suggest that "peripheral" 5-HT monitored in PRP is directly related to the levels of cerebral 5-HT [23-27]. The feasibility of selective monitoring of 5-HT by means of voltammetry together with specifically treated carbon fibre micro-electrodes (mCFE) has been demonstrated either in brain as well as in blood [28-32]. Furthermore, we have demonstrated that peripheral 5-HT levels monitored by means of differential pulse voltammetry (DPV) together with mCFE in rat PRP mirror cerebral 5-HT contents [28]. Therefore, in the present work, this electrochemical methodology has been applied to analyze daily the influence of behavioral-pharmacological tests upon in vivo serotonergic levels in the PRP of conscious rats. Substantially, monitoring "peripheral" 5-HT in PRP in alternative to the analysis of cerebral 5-HT avoids submitting the rats to: 1) Surgery performed under major reversible anesthesia i.e. chloral hydrate $[33,34]$ for implantation of the mCFE within the brain; ii) Daily substitution of the exhausted mCFE, performed under halotane anesthesia, when central 5-HT is monitored chronically [35].

\section{Material and Methods}

\subsection{Animals}

Male Sprague-Dawley CD rats and male Wistar rats (200-250g) were supplied by Charles-River (Italy) and were kept in temperature- and humidity-controlled rooms $\left(22^{\circ} \mathrm{C}, 50 \%\right)$ with lights on from 0700 to 1900 hours with water and food available ad libitum. All procedures were carried out in accordance with the Italian law (Legislative Decree no.116, 27 January 1992), which acknowledges the European Directive 86/609/EEC, and were fully compliant with GlaxoSmithKline policy on the care and use of laboratory animal and codes of practice. Furthermore, all efforts were made to minimize the number of animals used and their suffering.

\subsection{Behaviour Studies}

Rats were exposed to FST according to Porsolt et al. [1] except that the water was deeper so that rats cannot modify the effects of the forced swim by developing behavioral adaptations, such as when they touch the bottom or sides of the tank. Briefly, the animals were placed individually into a cylinder glass tank $[40 \mathrm{~cm}$ height; $20 \mathrm{~cm}$ diameter] containing water $30 \mathrm{~cm}$ deep and at $23-25^{\circ} \mathrm{C}$ according to Detke et al. [6] and Detke \& Lucki [4]. Two swim sessions were conducted i.e. a 15-min pre-test followed $24 \mathrm{~h}$ later by a 5 -min test.

Separate groups of rats received intraperitoneally either saline (Sprague-Dawley CD rats $n=5$; Wistar rats $n$ $=5$ ) or fluoxetine $20 \mathrm{mg} / \mathrm{kg}$ (Sprague-Dawley CD rats $\mathrm{n}$ $=6$; Wistar rats $\mathrm{n}=6$ ) in a volume of $2 \mathrm{ml} / \mathrm{kg}$. Each treatment was administered $23 \mathrm{~h}, 5 \mathrm{~h}$ and $1 \mathrm{~h}$ prior to the test as described earlier $[4,6]$. The $20 \mathrm{mg} / \mathrm{kg}$ dose of fluoxetine was also chosen because it has been demonstrated that in some animal models of anxiety, acute fluoxetine treatment may elicit a bell-shaped dose-response curve with a maximum effect at $20 \mathrm{mg} / \mathrm{kg}$ [36].

Other 5 Sprague-Dawley rats and 5 Wistar rats were exposed to a modified FST on four consecutive days. The modified test was called rFS as described earlier [15-17]. On the first day of $\mathrm{rFS}$, rats swam for $15 \mathrm{~min}$. subsequently they were removed from the water tank and dried under warm air. Other three swimming sessions of $5 \mathrm{~min}$ each were then conducted (spaced $24 \mathrm{~h}$ apart) on the following three days.

A time-sampling method was used as described previously [6] in order to score several behaviors during a single viewing. This method has been selected as it has shown to be reliable and valid for detecting the effect of different antidepressant drugs. In particular, immobility, swimming and climbing was monitored in 5-sec period. Briefly, immobility was scored when the animal was making the minimum movements necessary to keep its head above water and stay afloat. Swimming was scored when the animal actively swam around the tank, making movements greater than that necessary to stay afloat. Climbing was scored when the animal made vigorous thrashing movements with its forepaws in and out of water. It was usually directed against the wall of the tank. All the watching and scoring were performed by the 
same observer within the behavior tests.

\subsection{Voltammetric Studies}

Immediately after each forced swimming session, each rat was submitted to short (approximately $20 \mathrm{sec}$ ), light halotane anesthesia so that blood can be collected from tail vein (approximately $1 \mathrm{ml} /$ daily). The blood was centrifuged $15 \mathrm{~min}$ at $200 \mathrm{xg}$ at room temperature to obtain plasma rich-platelets (PRP) as described previously [37]. Successively, PRP was aspirated and re-suspended in PBS pH 7.4. Then, mCFE coated with Nafion (Nafion$\mathrm{mCFE})$ in order to selectively monitor serotonin [29,31, 38-41] were used in association with DPV to measure 5-HT content within PRP. More precisely, the mCFE and the other two electrodes needed to apply DPV: the auxiliary and the reference electrode [30,42] were inserted in $200 \mu l$ PRP obtained either from rats undergoing the behavioral test (rFS) or from naïve, control rats.

In order to verify the chemical nature of the DPV signal monitored in PRP as corresponding to the oxidation of 5-HT, the following experiments have been performed:

1) Addition of standard serotonin solution to PRP preparation;

2) Incubation during $10 \mathrm{~min}$ at room temperature in three $\mathrm{KCl}$ solutions $(150 \mu \mathrm{M}, 15 \mathrm{mM}$ or $150 \mathrm{mM}$, respectively).

3) Incubation during $10 \mathrm{~min}$ at room temperature in three EGTA solutions (3, 10, or $30 \mathrm{mM}$, respectively).

\subsection{Data Analyses}

All data were averaged and were expressed in percent of:

1) The averaged control 5-HT basal levels in the voltammetric analysis;

2) The averaged count of immobility behavior in vehicle treated rats in the FST study;

3) The averaged count of different behaviors of day 1 in the rFS study, respectively. However, the statistics were calculated from the raw data using repeated measures analysis of variance (two ways ANOVA) with STATISTICA software version 6.0. In the case of statistically significant differences between mean values produced by drug treatments versus controls (vehicle treatment) main factor Dunnet post-hoc test was applied. Statistical significance was set at $\mathrm{p}<0.05$.

\section{Results}

\subsection{Analysis of 5-HT Signal in PRP}

The use of Nafion-mCFE has permitted the selective analysis of 5-HT oxidation signal in PRP. This has been at first demonstrated by the good linearity in current levels monitored when progressive concentrations of ex- ogenous serotonin were added to PRP. It was also supported by the absence of electrical response following the addition of possible interfering substances that can oxidize at the specific oxidation potential of 5-HT such as uric acid and 5-OH-indoleacetic acid [43-45] (data not shown). It appeared that basal levels of 5-HT in the PRP of Wistar and Sprague-Dawley CD rats were similar: approximately $0.27 \pm 0.05 \mathrm{nA}$ and $0.22 \pm 0.06 \mathrm{nA}$, respectively. In addition, in both strains, the 5-HT signal monitored in PRP was progressively increased in the three $\mathrm{KCl}$ solutions, whilst it was reduced in a dose-dependent manner until disappearance in the three EGTA solutions (see Figure 1).

\subsection{FST and Fluoxetine}

When submitted to modified FST, significantly larger counts of immobility were monitored in the pre-test day and test day for Wistar rats versus Sprague-Dawley rats, i.e. 37.5 and 47.0 counts versus 25.3 and 38.7 counts, respectively.
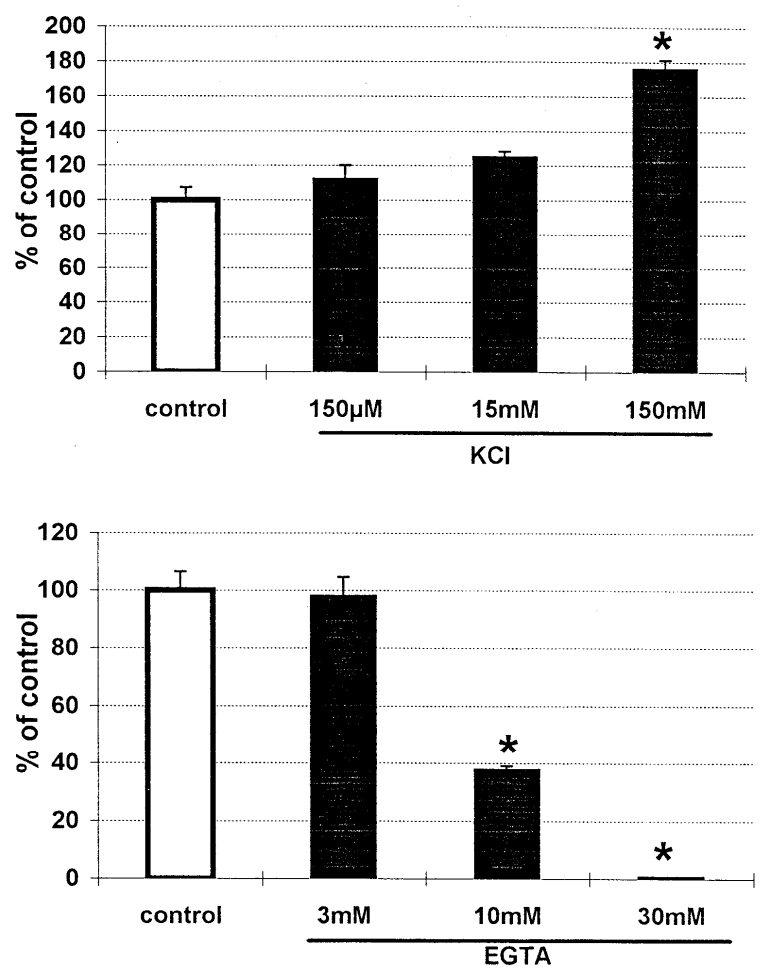

Figure 1. DPV analysis of 5-HT levels monitored with Nafion-mCFE in PRP incubated in KCl (TOP, $n=4$ samples each concentration) or in EGTA (BOTTOM, $n=4$ samples each concentration) during $10 \mathrm{~min}$ at room temperature. Data are expressed as percent of control values obtained in PRP maintained in PBS during $10 \mathrm{~min}$ at room temperature. ( $n=4$ samples). Mean \pm sem, $*$ p $<0.05$ 
Furthermore, in male Wistar rats pre-treated with fluoxetine $(20 \mathrm{mg} / \mathrm{kg}$ i.p.), behavioral observations indicated a significant increase of immobility up to $156.3 \%$ of control when submitted to FST in deeper water (30 $\mathrm{cm})$. In contrast, male Sprague-Dawley CD rats treated with fluoxetine $(20 \mathrm{mg} / \mathrm{kg}$ i.p.) and then submitted to FST did show a significant decrease of the immobility behavior to $79.4 \%$ of control (Figure 2). The two ways ANOVA test revealed significant effect of strain and treatment versus strain interaction (see Table 1).

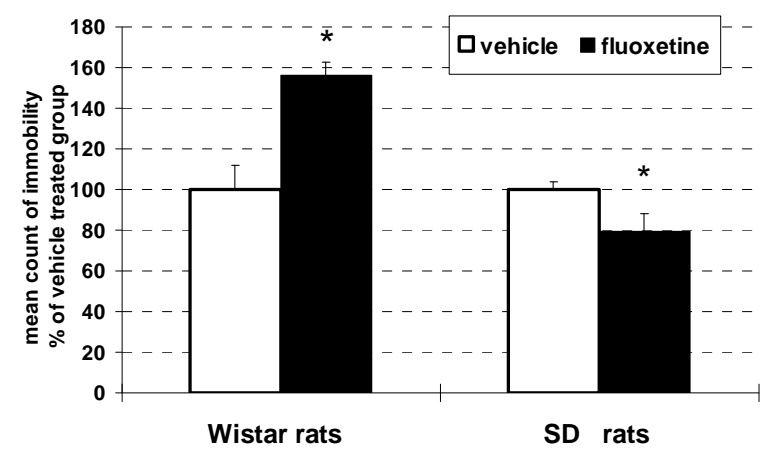

Figure 2. Effect of acute treatment with fluoxetine ( $20 \mathrm{mg} / \mathrm{kg}$ i.p.) on immobility behavior in Wistar rats or SpragueDawley CD (SD) rats $(n=6$ each strain) submitted to FST. Data are expressed as \% of control values obtained in vehicle treated rats ( $\square$ saline, $2 \mathrm{ml} / \mathrm{kg}$ i.p., $\mathrm{n}=5$ ). Mean \pm sem, * p $<0.05$

Table 1. Results of the two ways ANOVA test

\begin{tabular}{llcc}
\hline & Factor & F-value & p-value \\
\hline FST \& Fluoxetine & & & \\
Immobility & Treatment & 1.02 & 0.32 \\
& Strain & $\mathbf{5 . 4 0}$ & $\mathbf{0 . 0 3 3}$ \\
& Treatment vs. strain & $\mathbf{1 8 . 8}$ & $\mathbf{0 . 0 0 0 4}$ \\
rFS & & & \\
Immobility & Treatment & $\mathbf{9 . 8 3}$ & $\mathbf{0 . 0 0 0 1}$ \\
& Strain & $\mathbf{2 6 . 5}$ & $\mathbf{0 . 0 0 0 1}$ \\
& Treatment vs. strain & 0.11 & 0.95 \\
Climbing & Treatment & 2.41 & 0.085 \\
& Strain & $\mathbf{3 1 . 5}$ & $\mathbf{0 . 0 0 0 1}$ \\
& Treatment vs. strain & 1.91 & 0.15 \\
Swimming & Treatment & $\mathbf{1 5 . 2 4}$ & $\mathbf{0 . 0 0 0 1}$ \\
& Strain & $\mathbf{9 . 4 6}$ & $\mathbf{0 . 0 0 4 3}$ \\
& Treatment vs. strain & 1.11 & 0.36 \\
Voltammetry after & & & \\
rFS & & & \\
5-HT levels in PRP & Treatment & $\mathbf{1 5 . 3 8}$ & $\mathbf{0 . 0 0 0 1}$ \\
& Strain & $\mathbf{7 . 0 6}$ & $\mathbf{0 . 0 1 2}$ \\
& Treatment vs. strain & $\mathbf{3 . 6 2}$ & $\mathbf{0 . 0 2 4}$ \\
\hline & & &
\end{tabular}

\section{$3.3 \mathrm{rFS}$}

$\mathrm{rFS}$ has been performed during four days, including the first day pre-test. The counts of the three types of behavior analyzed (immobility, climbing, swimming) were taken in the first $5 \mathrm{~min}$ of the pre-test day and in the 5 min test of the successive three days. They revealed a similar trend of immobility in the two strains of rats; in particular Wistar rats displayed significantly $(p<0.05)$ greater rate of immobility than Sprague-Dawley CD rats: approx. 46.8 counts versus 38.2 counts, respectively (Figure 3). On the other hand, the two active behaviors climbing and swimming displayed different patterns in the two species of rats:

1) In Wistar rats, a significant decrease $(p<0.05)$ of the counts of climbing behavior was observed on the second day only; in the third and the fourth day the counts were similar to those of first day (Figure 3);

2) In Sprague-Dawley rats climbing behavior decreased significantly the third and fourth day (17.6 counts) versus the first day (26.2 counts) (Figure 3).
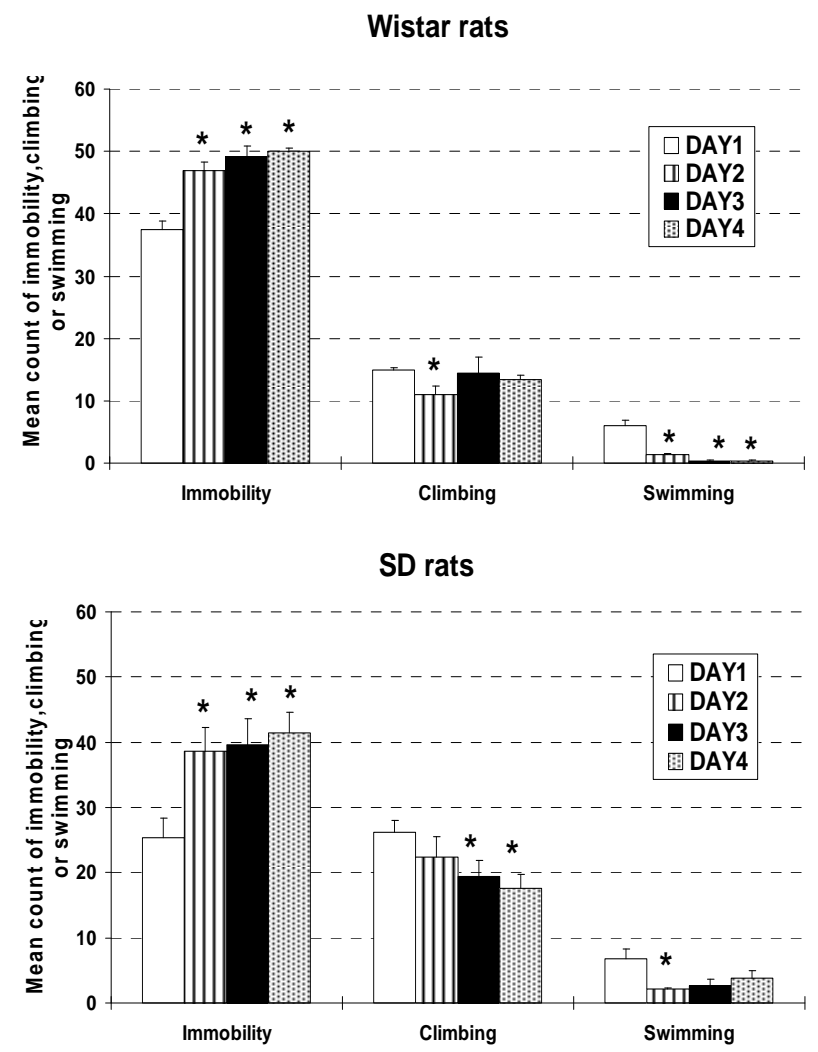

Figure 3. Counts of immobility, climbing and swimming behaviors sampled every $5 \mathrm{sec}$ during the first $5 \mathrm{~min}$ of pre-test day (day 1) and during the 5 min of the rFS (days 2-4) estimated in Wistar rats (TOP) or Sprague-Dawley CD (SD) rats $\left(\right.$ BOTTOM) $\left(n=5\right.$ each strain). Mean \pm sem, ${ }^{*} \mathbf{p}<$ 0.05 
Data obtained evaluating swimming in Wistar rats showed a rapid significant decrease of this behavior that was virtually disappeared during the third and fourth day of $\mathrm{rFS}$. In Sprague-Dawley rats swimming behavior presented a significant decrease at the second day versus the first day, but at the third and fourth day of $\mathrm{rFS}$ the swimming behavior returned to values not significantly different from those of the first day (Figure 3). The results of the two ways ANOVA test revealed significant main effects of treatment and strain in all behaviors apart from climbing where $\mathrm{p}$ value for treatment was 0.08 (Table 1).

\subsection{Voltammetry after rFS}

In both strains, 5-HT levels were electrochemically monitored within $200 \mu 1$ of PRP, daily.

The voltammetric results obtained in Wistar rats showed the 5-HT levels monitored in PRP decreased progressively; the third day of $\mathrm{rFS}$ they were significantly reduced to $71 \%$ of control values recorded in PRP of naïve rats. In contrast, in Sprague-Dawley rats, PRP-5-HT levels showed a significant increase at the first day of $\mathrm{rFS}$ while returning to values similar to those of control naïve rats the second and third day of the experiment (Figure 4). The results of the two ways ANOVA test revealed significant main effects of strain, treatment and strain by treatment interaction (see Table 1). In addition, significant correlation between swimming scores and 5-HT levels in PRP of the Wistar rats only has been determined: $r=0.53, p=0.015$.

\section{Discussion}

FST is described in the literature as a "behavioral despair" test $[1,3,4]$ as it produces a change in behavior i.e. an immobile posture that is considered "a key symptom of the depressive state, namely that of despair or helplessness" [3]. On the other hand it has been also suggested that the resulting behavior following FST could be due to the possibility that "the subject learns to be immobile in the first session", being the second one a "retention test" (learned immobility hypothesis) [18,21,22]. Furthermore, it is described that Wistar rats display less mobility than Sprague-Dawley CD rats when submitted to FST [11]. From these data one could hypothesize either that:

1) Wistar rats are more sensitive to stress than Sprague-Dawley $\mathrm{CD}$ rats and so their greater immobility could be correlated to a "behavioral despair"; or that:

2) Wistar rats display a greater memory and learning skills than Sprague-Dawley CD rats.

Therefore, in this study the hypothesis that the process involved in the FST could be "learning to be immobile" more than "behavioral despair" has been investigated in
Wistar rats and in Sprague-Dawley CD rats. Putative differences in behavior during FST or rFS (4 days) and the effect(s) of fluoxetine (SSRI) upon responses to FST were analyzed in these two strains.

At first we have confirmed data from the literature showing larger counts of immobility in Wistar rats versus Sprague-Dawley CD rats when submitted to FST (see Figure 3). Successively, a modified version of FST, so called rFS [15-17] has been applied so that putative differences in behavioral responses between Sprague-Dawley $\mathrm{CD}$ rats and Wistar rats could be evaluated.

Data show a significant increase of immobility in both strains within the second day of the rFS test and continuing the third and the fourth day of rFS in both types of rats (see Figure 3). Because of the numerous factors influencing the FST test, it has been suggested that the time
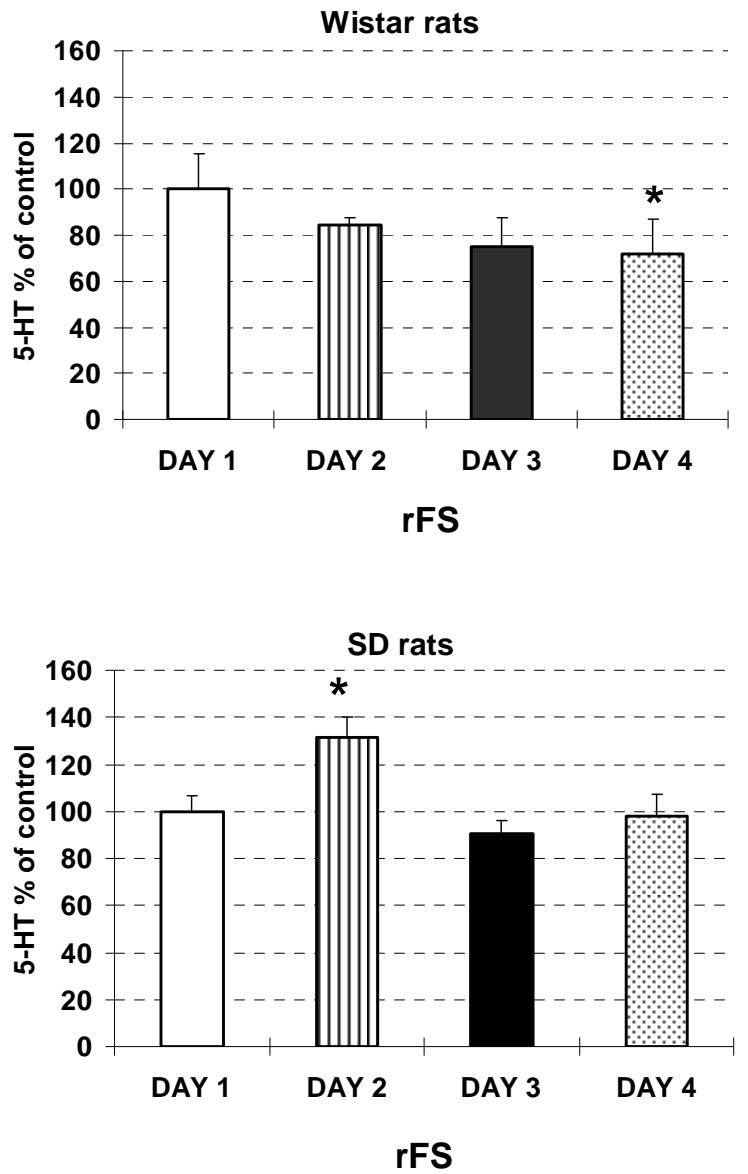

Figure 4. Influence of rFS upon DPVoltammetric 5-HT levels monitored in PRP prepared from blood collected daily at the end of each FS session from tail vein of Wistar $(n=5)$ or Sprague-Dawley CD $(n=5)$ rats. Data are expressed as percent of control values obtained by measuring 5-HT levels in PRP prepared from blood of five naïve rats. Mean \pm sem, $* \mathbf{p}<0.05$ 
of immobility on the second day of rFS might be considered a nonspecific parameter referred to as "learning to be immobile" rather than "behavioral despair" [21]. The present data also show that treatment with fluoxetine actually increases immobility as well. Since fluoxetine is a compound that inhibits serotonin reuptake, thus making it more available at its receptors, this result could appears like a contradiction, however in the Porsolt' test the SSRIs have been found to be ineffective or even prolonging the time of immobility [6,46]. Similarly, while in the literature, the results concerning the ineffectiveness of the SSRIs in rats are still controversial, it has been constantly reported that the SSRIs extend the time of immobility in mice [46]. It is also well known that acute treatment with SSRIs may produce anxiogenic-like effects in humans [47] as well as in animals [48]. Furthermore, Borsini et al. [49] have indirectly illustrated that the emotional state of an animal might be important for the outcome of the test. Accordingly, our data show that Wistar rats display greater immobility and that is in agreement to the reported observation that such an inbred rat strain is inclined to higher behavioral and physiological responses to stress across a variety of situations in comparison to other strains [15]. This would also explain the significant decrease of swimming mainly observable in Wistar rats.

\subsection{Voltammetry in PRP}

Concomitant in vivo DPVoltammetric analysis performed accordingly with Zen et al. [32] has shown that the signal monitored with Nafion-mCFE in PRP at the oxidation potential of 5-HT was selectively sensitive to addition of exogenous 5-HT (data not shown). Furthermore, experiments performed in PRP accordingly with Barja-Fidalgo et al. [50] have shown that incubation in $\mathrm{KCl}$ stimulates increase of the 5-HT related DPV signal. Finally, accordingly with Lyons and Shaw [51] treatment of PRP with the calcium-chelating agent EGTA has demonstrated a dose dependent reduction of the 5-HT related signal (see Figure 1). Thus, these DPVoltammetric data support the chemical nature of the signal monitored in PRP as corresponding to the oxidation of basal, endogenous 5-HT level in PRP. Successively, DPV measurements performed during the behavioral tests showed that 5-HT level in PRP decreased progressively in Wistar rats submitted to $\mathrm{rFS}$, while they increased at day 1 of $\mathrm{rFS}$ in Sprague-Dawley rats and returned to control levels the next days. The fact that "peripheral" 5-HT levels [in PRP] mirror central 5-HT levels has been already documented [23-27]. Therefore the present data on 5-HT level in PRP of Wistar rats taken together with the observation that pharmacological blockade of serotonergic activity enhance learning and memory skills $[19,20]$ may suggest that the increased immobility fol- lowing $\mathrm{rFS}$ monitored in Wistar rats could be due to "learning to be immobile" more than "behavioral despair". Thus, the concomitant decrease of 5-HT levels monitored in PRP and considered as peripheral marker of modifications of central 5-HT system may be correlated to the enhancement of learning skill; i.e. it could lead Wistar rats to develop habituation to be immobile when submitted to rFS. Conversely, other authors have reported that serotonin receptor agonists deteriorate such skills [52,53], therefore the hypothesis proposed above is still matter of discussion. When related to the same observation reported above $[19,20]$ the significant increase of 5-HT level in PRP of Sprague-Dawley CD rats leads one to consider that in this strain of rats the significant increase of immobility following $\mathrm{rFS}$ could be unrelated to "learning to be immobile" but may be interpreted in the light of a "behavioral despair" hypothesis. However, this conclusion is in disaccord with the finding that (diet) tryptophan restriction, and therefore brain serotonin reduction, could impair normal cholinergic activity in some brain areas such as the hippocampus and the cerebral cortex that are involved in learning and memory processes [54]. These observations lead to the comment that work remains to be done to further elucidate the contrasting data present in literature on this matter. Decreased levels of central 5-HT has been recently reported in Wistar rats submitted to rFS [55]. Our voltammetric data on 5-HT levels monitored in PRP of Wistar rats match these recent findings which therefore support the proposal that peripheral 5-HT levels monitored by means of DPV together with mCFE in rat PRP mirror cerebral 5-HT contents.

Furthermore and on the basis of the 5-HT hypothesis of depression suggesting a relationship between vulnerability to this illness and a deficit in the brain serotonergic activity [56] the depletion of 5-HT caused by forced swimming may be one of the reasons for the development of depressive-like behavior in Wistar rats.

On the other hand, the observation of an increased level of 5-HT on day 2 returning to "control" values on days 3 and 4 in the PRP of Sprague-Dawley CD rats lead one to propose that there is not such a central 5-HT deficit in this second strain of rats. This is supporting the idea that $\mathrm{rFS}$ may display learning behavior in Sprague-Dawley $\mathrm{CD}$ rats as the present results suggest that experience and learning may be the principal processes at the basis of the significant increase of immobility in Sprague-Dawley CD. Indeed, in these rats, immobility levels were continuously increasing during the 3 days of rSF following the pre-test day (day 1, see Figure 3), without reaching a plateau while showing higher variability on their response when compared to that of Wistar rats (see Figure 3). In contrast, the Wistar rats submitted to $\mathrm{rFS}$ present less mobility than the Sprague-Dawley CD 
rats; i.e. they show less variability on their response (see Figure 3 top) and reach a stable (plateau) level of immobility the third and fourth day of the test. Thus, "behavioral despair" seems to be the cause of the increased immobility in Wistar rats as their "answer" to the recurring stress produced by the repetition of the test is the 'sudden' increased immobility to a plateau as indeed found at the third and fourth day of rFS. Accordingly with previous studies indicating that various stressors alter 5-HT synthesis / turnover [57,58], the different behavior within these two strains may therefore also be related to the different biochemical "reaction" of their 5-HT central system when submitted to FST: i.e. progressive decrease of 5-HT levels in Wistar rats versus a significant increase in day 1 followed by return to control values days 2 and 3 in Sprague-Dawley CD rats (Figure 4).

The present study also shows a rapid decrease of swimming until virtually its disappearance during the third-fourth day of rFS in Wistar rats. In contrast, in Sprague-Dawley rats swimming behavior presented a significant decrease at the second day versus the first testing day, but at the third and fourth day it returned to values not significantly different from those recorded in the first day of rFS. Again, this difference in swimming behavior between the two strains of rats could be related to the difference in 5-HT levels monitored after each swimming session in PRP of both species of rats. In Wistar rats 5-HT levels monitored in PRP decreased progressively; reaching the minimum significant value at the third day of rFS. In Sprague-Dawley rats, 5-HT levels in PRP showed a significant increase at the first day of rFS, returning to values similar to those of control rats the following days of experiment. This is in accord with the relationship described in literature between serotonergic system activities and swimming behavior during FST: in particular an enhancement of 5-HT neurotransmission mediates positively the swimming behavior of Sprague-Dawley CD rats $[4,6]$.

Moreover, it is interesting to note the different climbing behavior displayed by the two rat strains when submitted to rFS:

1) Progressive decrease of climbing in Sprague-Dawley CD rats;

2) Initial decrease followed by a return to the values of day 1 in Wistar rats.

Therefore, when submitted to rFS, these two strains of rats display opposite swimming and climbing behaviors (see Figure 3). Briefly:

1) In Wistar rats climbing at first decreased [day 2] then restored the levels of dayl while swimming decreased progressively;

2) In Sprague-Dawley CD rats climbing decreased progressively while swimming at first decreased [day 2] then tended to return to the initial levels.

It is reported that climbing is a behavior mediated by noradrenergic neurotransmission and swimming a behavior mediated by serotonergic neurotransmission $[4,6]$. Thus, one can argue that the behavioral data monitored here, could be an index of distinct activities of the two neurotransmitter systems within the two strains of rats when submitted to FST as well as to rFS. In particular, the dissimilarity observed within the serotonergic system of the two strains i.e. when submitted to $\mathrm{rFS}$ may account for the different behavioral response to fluoxetine treatment observed here i.e. either increase or reduction of immobility in Wistar rats or in Sprague-Dawley CD rats, respectively (see Figure 2). Accordingly, the data concerning swimming counts led one to argue about the additional presence of a divergent activity of the noradrenergic system in the two rat strains during FST or rFS. Further studies should be done to analyze this point. Yet, it is interesting to note the parallel, significantly related decrease of swimming counts and 5-HT levels monitored in PRP of the Wistar rats submitted to rFS (see Figure 5). Taken together with the findings that reductions of noradrenaline or 5-HT, which do not by themselves impair place learning, aggravate the place-learning deficit produced by reductions of Ach [59] the present data support the idea that in Wistar rats the increased immobility following rFS could be due to "behavioral despair" more than "learning to be immobile". On the contrary, the lack of change on 5-HT levels as well as in swimming behavior observed in the Sprague-Dawley CD rats may suggest that the increased immobility following rFS could be due to "learning to be immobile" more than "behavioral despair".

Differential sensitivity to the behavioral effects of fluoxetine by different rat strains has been already reported. In particular it has been shown that genetic or constitutive differences may determine the distinct behavioral profiles for antidepressant compounds with selective pharmacological effects in different rat strains such as male Sprague Dawley and Wistar Kyoto rats [11, $60]$. The latter is a line derived from Wistar rats, presenting significant higher plasma levels of corticosterone and ACTH compared to Wistar rats that are the "control line" of the Wistar Kyoto rats [61]. On the other hand, these authors have also shown that Wistar rats exhibited significantly longer immobility duration in the swim test compared with the Sprague-Dawley CD rats. This is in accord with the present observation of a significantly higher counts of immobility in Wistar rats versus Sprague-Dawley CD rats submitted to rFS (see Figure 3 and Table 1). Altogether such results suggest that different rat strains may demonstrate great variability in the behavioral response to antidepressants according to their genetic or constitutive differences as well as pharmacological selectivity, differences that should be not ruled out 

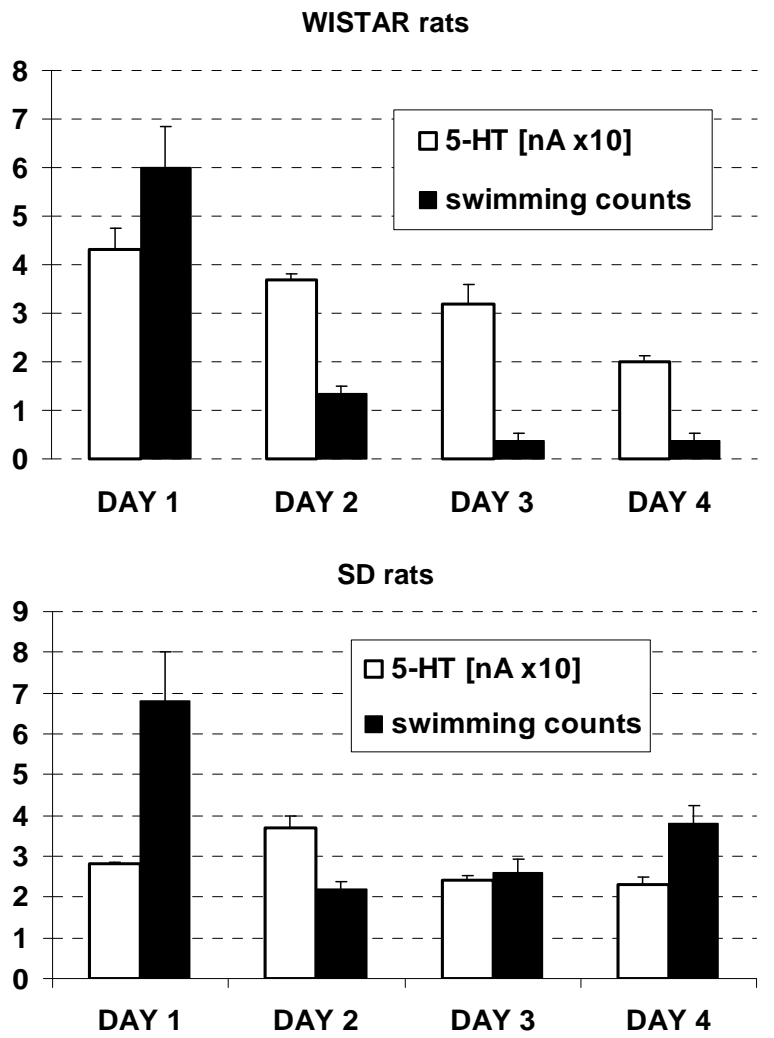

Figure 5. Influence of rFS upon swimming and DPVoltammetric 5-HT levels monitored in PRP prepared from blood collected daily at the end of each FS from tail vein of Wistar rats $(n=5)$ or Sprague-Dawley $C D$ rats $(n=5)$. Mean counts ( \pm sem) are shown together with 5-HT levels (i.e. nanoAmperes [nA] multiplied by 10 for graphic purpose). Significant correlation between swimming scores and 5-HT levels in PRP of Wistar rats has been determined: $r=0.53$, $\mathbf{p}=\mathbf{0 . 0 1 5}$

when evaluating behavioral and neurochemical changes in response to antidepressants such as fluoxetine. In this sense, it is worth mentioning that it has recently been shown that four 5-HT receptor systems $\left(5-\mathrm{HT}_{1 \mathrm{~A}}, 5-\mathrm{HT}_{2 \mathrm{~A}}\right.$, $\left.5-\mathrm{HT}_{4}, 5-\mathrm{HT}_{6}\right)$ are highlighted as suitable targets for enhancing cognition and memory (for a review see [62]) with in particular the $5-\mathrm{HT}_{6}$ receptor playing a role in learning and memory processes in healthy and disease states (see reviews by Mitchell and Neumaier [63] and Schreiber et al. [64]). The putative synergistic interaction of 5-HT6 receptors with other serotonin receptors is also shown to be important for memory processes [65]. Therefore, differences in such aspects within the different strains of rats may also account for the variability in behavioral responses.

\section{Conclusions}

In conclusion, the present in vivo electrochemical analysis support our previous work showing that peripheral
5-HT levels selectively monitored in rat PRP by means of DPV together with Nafion-mCFE mirror cerebral 5-HT contents [28]. In particular it allows deducing changes of central 5-HT levels that could be correlated to behavioral tests such as FST or rFS. Therefore, this in vivo approach displays the clear advantage of non invasive behavioral-pharmacological analysis of neurotransmitter activities in conscious animals. Finally, while further work is needed to support the following idea, the combined behavioral-pharmacological data presented suggest that "learning to be immobile" seems to be the process involved in Sprague-Dawley CD rats submitted to rFS while "behavioral despair" seems to be the process involved in Wistar rats submitted to $\mathrm{rFS}$.

\section{Acknowledgements}

For technical support to Dr. E. Vecchiato and Dr. C. Lazzarini.

\section{REFERENCES}

[1] R. D. Porsolt, M. Le Pichon and M. Jalfre, "Depression: A New Animal Model Sensitive to Anti Depressant Treatments," Nature, Vol. 266, No. 5604, 1977, pp. 730-732.

[2] F. Borsini and A. Meli, "Is the Forced Swimming Test a Suitable Model for Revealing Antidepressant Activity?" Psychopharmacology, Vol. 94, No. 2, 1988, pp. 147-160.

[3] T. J. Connor, P. Kelliher, Y. Shen, A. Harkin, J. P. Kelly and B. E. Leonard, "Effect of Subchronic Antidepressant Treatments on Behavioral, Neurochemical, and Endocrine Changes in the Forced-Swim Test," Pharmacology Biochemistry and Behavior, Vol. 65, No. 4, 2000, pp. 591-597.

[4] M. J. Detke and I. Lucki, "Detection of Serotonergic and Noradrenergic Antidepressants in the Rat Forced Swimming Test: The Effect of Water Depth," Behavioural Brain Research, Vol. 73, No. 1-2, 1996, pp. 43-46.

[5] R. D. Porsolt, A. Bertin, N. Blavet, M. Deniel and M. Jalfre, "Immobility Induced by Forced Swimming in Rats: Effects of Agents which Modify Central Catecholamine and Serotonin Activity," European Journal of Pharmacology, Vol. 57, No. 2-3, 1979, pp. 201-210.

[6] M. J. Detke, M. Rickels and I. Lucki, "Active Behaviors in the Rat Forced Swimming Test Differentially Produced by Serotonergic and Noradrenergic Antidepressants," Psychopharmacology, Vol. 121, No. 1, 1995, pp. 66-72.

[7] S. E. Hemby, I. Lucki, G. Gatto, A. Singh, C. Thornley, J. Matasi, N. Kong, J. E. Smith, H. M. L. Davies and S. I. Dworkin, "Potential Antidepressant Effects of Novel Tropane Compounds, Selective for Serotonin or Dopamine Transporters," Journal of Pharmacology and Experimental Therapeutics, Vol. 282, No. 2, 1997, pp. 727-733.

[8] L. G. Kirby and I. Lucki, "Interaction between the Forced Swimming Test and Fluoxetine Treatment on Extracellular 5-Hydroxytryptamine and 5-Hydroxyindoleacetic Acid in the Rat," Journal of Pharmacology and Experimental Therapeutics, Vol. 282, No. 2, 1997, pp. 967-976. 
[9] M. E. Page, M. J. Detke, G. Kirby and I. Lucki, "Serotonergic Mediation of the Effects of Fluoxetine, but not Desipramine, in the Rat Forced Swimming Test," Psychopharmacology, Vol. 147, No. 2, 1999, pp. 162-167.

[10] J. P. Reneric and I. Lucki, "Antidepressant Behavioral Effects by Dual Inhibition of Monoamine Reuptake in the Rat Forced Swimming Test," Psychopharmacology, Vol. 136, No. 2, 1998, pp. 190-197.

[11] C. López-Rubalcava and I. Lucki, "Strain Differences in the Behavioral Effects of Antidepressant Drugs in the Rat Forced Swimming Test," Neuropsychopharmacology, Vol. 22, No. 2, 2000, pp. 191-199.

[12] T. Skrebuhhova, L. Allikmets and V. Matto, "Effect of Anxiogenic Drugs in Rat Forced Swimming Test," Methods \& Findings in Experimental \& Clinical Pharmacology, Vol. 21, No. 3, 1999, pp. 173-178.

[13] J. De Vry, S. Maurel, R. Schreiber, R. de Beun and K. R. Jentzsch, "Comparison of Hypericum Extracts with Imipramine and Fluoxetine in Animal Models of Depression and Alcoholism," European Neuropsychopharmacology, Vol. 9, No. 6, 1999, pp. 461-468.

[14] G. Griebel, C. Cohen, G. Perrault and D. J. Sanger, "Behavioral Effects of Acute and Chronic Fluoxetine in Wistar-Kyoto Rats," Physiology \& Behavior, Vol. 67, No. 3, 1999, pp. 315-320.

[15] J. F. Cryan, M. E. Page and I. Lucki, "Differential Behavioral Effects of the Antidepressants Reboxetine, Fluoxetine, and Moclobemide in a Modified Forced Swim Test Following Chronic Treatment," Psychopharmacology (Berl), Vol. 182, No. 3, 2005, pp. 335-339.

[16] S. Dal-Zotto, O. Marti and A. Armario, "Influence of Single or Repeated Experience of Rats with Forced Swimming on Behavioral and Physiological Responses to the Stressor," Behavioural Brain Research, Vol. 114, No. 1-2, 2000, pp. 175-181.

[17] L. G. Kirby and I. Lucki, "The Effect of Repeated Exposure to Forced Swimming on Extracellular Levels of 5-Hydroxytryptamine in the Rat," Stress, Vol. 2, No. 4, 1998, pp. 251-263.

[18] A. Parra, C. Vinader-Caerols, S. Monleón and V. M. Simón, "Learned Immobility is also Involved in Forced Swimming Test in Mice," Psicothema, Vol. 11, No. 2, 1999, pp. 239-246.

[19] Y. Lamberty and A. J. Gower, "Cholinergic Modulation of Spatial Learning in Mice in a Morris-Type Water Maze," Archives Internationales de Pharmacodynamie et de Therapie, Vol. 309, 1991, pp. 5-19.

[20] G. Richter-Levin and M. Segal, "The Effect of Serotonin Depletion and Raphe Grafts on Hippocampal Electrophysiology and Behavior," Journal of Neuroscience, Vol. 11, No. 6, 1991, pp. 1585-1596.

[21] J. M. De Pablo, A. Parra, S. Segovia and A. Guillamon, "Learned Immobility Explains the Behavior of Rats in the Forced Swimming Test," Physiology \& Behavior, Vol. 46, No. 2, 1989, pp. 229-237.

[22] A. J. Martos, C. Vinader-Caerols, S. Monleón, M. C. Are- nas and A. Parra, "Effect of Physostigmine and Nicotine on Learned Immobility in the Forced Swimming Test," Psicothema, Vol. 11, No. 3, 1999, 631-639.

[23] E. H. Cook, K. E. Fletcher, M. Wainwright, N. Marks, S. Y. Yan and B. L. Leventhal, "Primary Structure of the Human Platelet Serotonin 5- $\mathrm{HT}_{2 \mathrm{~A}}$ Receptor: Identity with Frontal Cortex Serotonin 5- $\mathrm{HT}_{2 \mathrm{~A}}$ Receptor," Journal of Neurochemistry, Vol. 63, No. 2, 1994, pp. 465-469.

[24] C. R. Pfeffer, P. A. McBride, G. M. Anderson, T. Kakuma, L. Fensterheim and V. Khait, "Peripheral Serotonin Measures in Prepubertal Psychiatric Inpatients and Normal Children: Association with Suicidal Behavior and its Risk Factors," Biological Psychiatry, Vol. 44, No. 7, 1988, pp. 568-577.

[25] S. D. Mendelson, "The Current Status of the Platelet 5-HT $2 \mathrm{~A}$ Receptor in Depression," Journal of Affective Disorders, Vol. 57, No. 1, 2000, pp. 13-24.

[26] J. M. Sneddon, "Blood Platelets as a Model for Monoamine Containing Neurones," Progress in Neurobiology, Vol. 1, No. 2, 1973, pp. 151-198.

[27] S. M. Stahl, "The Human Blood Platelet: A Diagnostic and Research Tool for the Study of Biogenic Amines in Psychiatric and Neurologic Disorders," Archives of General Psychiatry, Vol. 34, No. 5, 1977, pp. 509-516.

[28] M. Bianchi, C. Moser, C. Lazzarini, E. Vecchiato and F. Crespi, "Forced Swimming Test and Fluoxetine Treatment: In Vivo Evidence that Peripheral 5-HT in Rat Platelet-Rich Plasma Mirrors Cerebral Extracellular 5-HT Levels, whilst 5-HT in Isolated Platelets Mirrors Neuronal 5-HT Changes," Experimental Brain Research, Vol. 143, No. 2, 2002, pp. 191-197.

[29] F. Congestri, F. Formenti, V. Sonntag and F. Crespi, "The Selective D3 Receptor Antagonist SB-277011-A Potentiates the Effect of Cocaine on Extracellular Dopamine in the Nucleus Accumbens: A Dual Core-Shell Voltammetry Study in Anesthetized Rats," Sensors, Vol. 8, No. 11, 2008, pp. 6936-6951.

[30] F. Crespi, "In Vivo Voltammetry with Micro-Biosensors for Analysis of Neurotransmitter Release and Metabolism," Journal of Neuroscience Methods, Vol. 34, No. 1-3, 1990, pp. 53-65.

[31] F. Crespi, K. F. Martin and C. A. Marsden, "Measurement of Extracellular Basal Levels of Serotonin in Vivo Using Nafion-Coated Carbon Fibre Electrodes Combined with Differential Pulse Voltammetry," Neuroscience, Vol. 27, No. 3, 1988, pp. 885-896.

[32] J.-M. Zen, I.-L. Chen and Y. Shih, "Voltammetric Determination of Serotonin in Human Blood Using a Chemically Modified Electrode," Analytica Chimica Acta, Vol. 369, No. 1-2, 1998, pp. 103-108.

[33] F. Crespi, "In Vivo Voltammetry and Concomitant Electrophysiology at a Single Biosensor to Analyse Ischaemia, Depression and Drug Dependence," Journal of Neuroscience Methods, Vol. 119, No. 2, 2002, pp. 173-184.

[34] F. Crespi and M. Jouvet, "Differential Pulse Voltammetry: Parallel Peak 3 Changes with Vigilance States in Raphe 
Dorsalis and Raphe Magnus of Chronic Freely Moving Rats and Evidence for 5HT Contribution to this Peak after Monoamine Oxidase Inhibitors," Brain Research, Vol. 272, No. 2, 1983, pp. 263-268.

[35] A. Louilot, A. Serrano and M. D'Angio, "A Novel Carbon Fiber Implantation Assembly for Cerebral Voltammetric Measurements in Freely Moving Rats," Physiology \& Behavior, Vol. 41, No. 3, 1987, pp. 227-231.

[36] S. L. Handley and J. W. McBlane, "Opposite Effects of Fluoxetine in Two Animal Models of Anxiety," British Journal of Pharmacology, Vol. 107S, 1997, p. 446.

[37] M. L. Rao, B. Hawellek, A. Papassotiropoulos, A. Deister and C. Frahnert, "Upregulation of the Platelet Serotonin ${ }_{2 \mathrm{~A}}$ Receptor and Low Blood Serotonin in Suicidal Psychiatric Patients," Neuropsychobiology, Vol. 38, No. 2, 1998, pp. 84-89.

[38] F. Crespi, "Apamin Increases 5-HT Cell Firing in Raphe Dorsalis and Extracellular 5-HT Levels in Amygdala: A Concomitant in Vivo Study in Anesthetized Rats," Brain Research, Vol. 1281, 2009, pp. 35-46.

[39] K. F. Martin, C. A. Marsden and F. Crespi. "In Vivo Electrochemistry with Carbon Fibre Electrodes: Principles and Application to Neuropharmacology," Trends in Analytical Chemistry, Vol. 7, No. 9, 1988, pp. 334-339.

[40] J. A. Stamford, F. Crespi and C. A. Marsden, "In Vivo Voltammetric Methods for Monitoring Monoamine Release and Metabolism," Monitoring Neuronal Activity, a Practical Approach, Oxford University Press, Oxford, 1992, pp. 113-145.

[41] T Self and F. Crespi, "Electron Microscopic and Voltammetric Analysis of Carbon Fibre Electrode Pretreatments," Journal of Materials Science: Materials in Medicine, Vol. 3, No. 6, 1992, pp. 418-425.

[42] F. Crespi and Z. L. Rossetti, "Pulse of Nitric Oxide Release in Response to Activation of N-Methyl-D-Aspartate Receptors in the Rat Striatum: Rapid Desensitisation, Inhibition by Receptor Antagonists and Potentiation by Glycine," Journal of Pharmacology and Experimental Therapeutics, Vol. 309, No. 2, 2004, pp. 462-468.

[43] F. Crespi, T. Sharp, N. Maidment and C. A. Marsden, "Differential Pulse Voltammetry in Vivo-Evidence that Uric Acid Contributes to the Indole Oxidation Peak," Neuroscience Letters, Vol. 43, No. 2-3, 1983, pp. 203-207.

[44] F. Crespi, T. Sharp, N. Maidment and C. A. Marsden, "Differential Pulse Voltammetry: Simultaneous in Vivo Measurement of Ascorbic Acid, Catechols and 5-Hydroxyindoles in the Rat Striatum Using a Single Carbon Fibre Electrode," Brain Research, Vol. 322, No. 1, 1984, pp. 135138.

[45] F. Crespi, P. Keane and M. Morre, "Does Concomitant Analysis of Extracellular DOPAC and 5HIAA with a Single Carbon Fibre Electrode Enable the Detection of Striatal Dopamine-Serotonin Interaction?" Journal of Neurochemistry, 1985, Vol. 44, pp. 109-112.

[46] F. Borsini, "Role of the Serotonergic System in the Forced Swimming Test," Neuroscience \& Biobehavioral Reviews,
Vol. 19, No. 3, 1995, pp. 377-395.

[47] W. F. Boyer and J. P. Feighner, "Side Effects of the Selective Serotonin Re-Uptake Inhibitors," In: J. P. Feighner and W. F. Boyer, Ed., Selective Serotonin Re-Uptake Inhibitors. Perspectives in Psychiatry 1, Wiley Press, New York, 1991, pp. 133-152.

[48] P. Chopin and M. Briley, "Animal Models of Anxiety: The Effect of Compounds that Modify 5-HT Neurotransmission," Trends in Pharmacological Sciences, Vol. 8, No. 10, 1987, pp. 383-388.

[49] F. Borsini, A. Lecci, A. Sessarego, R. Frassine and A. Meli, "Discovery of Antidepressant Activity by Forced Swimming Test may Depend on Pre-Exposure of Rats to a Stressful Situation," Psychopharmacology, Vol. 97, No. 2, 1989, pp. 183-188.

[50] C. Barja-Fidalgo, J. A. Guimaraes and C. R. Carlini, "The Secretory Effect of Canatoxin on Rat Brain Synaptosomes Involves A Lipoxygenase-Mediated Pathway," Brazilian Journal of Medical and Biological Research, Vol. 21, No. 3, 1988, pp. 549-552.

[51] R. M. Lyons and J. O. Shaw, "Interaction of $\mathrm{Ca}^{2+}$ and Protein Phosphorylation in the Rabbit Platelet Release Reaction," Journal of Clinical Investigation, Vol. 65, No. 2, 1980, pp. 242-255.

[52] H. C. Buhot, S. Martin and L. Segu, "Role of Serotonin in Memory Impairment," Annals of Medicine, Vol. 32, No. 3, 2000, pp. 210-221.

[53] W. J. McEntee and T. H. Crook, "Serotonin, Memory, and the Aging Brain," Psychopharmacology, Vol. 103, No. 2, 1991, pp. 143-149.

[54] I. Gonzalez-Burgos, M. I. Perez-Vega, A. R. Del AngelMeza and A. Feria-Velasco, "Effect of Tryptophan Restriction on Short-Term Memory," Physiology \& Behavior, Vol. 63, No. 2, 1998, pp. 165-169.

[55] G. T. Shishkina, T. S. Kalinina and N. N. Dygalo, "Serotonergic Changes Produced by Repeated Exposure to Forced Swimming: Correlation with Behavior," Annals of the New York Academy of Sciences, Vol. 1148, 2008, pp. 148-153.

[56] M. H. Maes and Y. Meltzer, "The Serotonin Hypothesis of Major Depression,” In: F. E. Bloom and D. J. Kupfer, Ed., Psychopharmacology: The Fourth Generation of Progress, Raven Press, New York, 1995, pp. 933-944.

[57] F. Chaouloff, "Physiopharmacological Interactions between Stress Hormones and Central Serotonergic Systems," Brain Research Reviews, Vol. 18, No. 1, 1993, pp. 1-32.

[58] L. E. Rueter, C. A. Fornal and B. L. Jacobs, "A Critical Review of 5-HT Brain Microdialysis and Behavior," Reviews in the Neurosciences, Vol. 8, No. 2, 1997, pp. 117-137.

[59] R. K. McNamara and R. W. Skelton, "The Neuropharmacological and Neurochemical Basis of Place Learning in the Morris Water Maze," Brain Research Reviews, Vol. 18, No. 1, 1993, pp. 33-49.

[60] S. Tejani-Butt, J. Kluczynski and W. P. Paré, "StrainDependent Modification of Behavior Following Antide- 
pressant Treatment," Progress in Neuro-Psychopharmacology \& Biological Psychiatry, Vol. 27, No. 1, 2003, pp. 7-14.

[61] O. Malkesman, Y. Braw, R. Maayan, A. Weizman, D. H. Overstreet, M. Shabat-Simon, Y. Kesner, et al., "Two Different Putative Genetic Animal Models of Childhood Depression," Biological Psychiatry, Vol. 59, No. 1, 2006, pp. 17-23.

[62] B. L. Roth, S. M. Hanizavareh and A. E. Blum, "Serotonin Receptors Represent Highly Favorable Molecular Targets for Cognitive Enhancement in Schizophrenia and Other Disorders," Psychopharmacology, Vol. 174, No. 1, 2004, pp. 17-24.

[63] E. S. Mitchell and J. F. Neumaier, "5- $\mathrm{HT}_{6}$ Receptors: A
Novel Target for Cognitive Enhancement," Pharmacology \& Therapeutics, Vol. 108, No. 3, 2005, pp. 320-333.

[64] R. Schreiber, A. J. Sleight and M. L. Woolley, "5-HT Receptors as Targets for the Treatment of Cognitive Deficits in Schizophrenia," In: B. R. Roth, Ed., Serotonin Receptors: From Molecular Pharmacology to Human Therapeutics, Humana Press, Totowa, 2006, pp. 495-515.

[65] E. S. Mitchell, B. J. Hoplight, S. P. Lear and J. F. Neumaier, "BGC20-761, a Novel Tryptamine Analog, Enhances Memory Consolidation and Reverses Scopolamine-Induced Memory Deficit in Social and Visuospatial Memory Tasks through a 5-HT 6 Receptor-Mediated Mechanism," Neuropharmacology, Vol. 50, No. 4, 2006, pp. 412-420. 